\title{
An Experimental Investigation on Addition of Bentonite on Tannery Wastewater Characteristics
}

\author{
Mohamed Ahmed Adam Khdam ${ }^{1}$, Abusabah E. Elemam², Mohamedabusgra E. Elmam ${ }^{3}$ \\ ${ }^{1}$ Faculty of Engineering, University of Khartoum, Civil Eng. Dept., Khartoum, Sudan \\ ${ }^{2}$ College Water and Environmental Engineering, Sudan University of Science and Technology (SUST), Water Resources Eng. Dept., \\ Khartoum, Sudan \\ ${ }^{3}$ Aksad Consulting Company, Khartoum, Sudan
}

\section{Email address:}

abusabah@sustech.edu (A. E. Elemm), abusabah88674@gmail.com (A. E. Elemm), abusgra15190@gmail.com (M. E. Elmam)

\section{To cite this article:}

Mohamed Ahmed Adam Khdam, Abusabah E. Elemm, Mohamedabusgra E. Elmam. An Experimental Investigation on Addition of Bentonite on Tannery Wastewater Characteristics. International Journal of Fluid Mechanics \& Thermal Sciences. Vol. 1, No. 2, 2015 , pp. $25-29$. doi: $10.11648 /$ j.ijfmts.20150102.12

\begin{abstract}
In this study, wastewater generated from Africa tannery in Khartoum North was investigated for removing of chromium from a wastewater by utilizing Bentonite. Experiments were carried out in order to obtain the optimum dose of Bentonite to be applied for the best removal of chromium and other wastewater parameters which include chemical oxygen demand, Oil and grease, total suspended solid, and chloride. For a 15mg/L dose of Bentonite removal rates of 99\%, 44\%, 94\%, $75 \%$ and $53 \%$ of chromium $(\mathrm{Cr})$, chemical oxygen demand (C.O.D), total suspended solid (T.S.S) and chloride (Cl) were respectively obtained. The Removal time for the above dose $15 \mathrm{mg} / \mathrm{L}$ was 6 hours. The results of the test were statistically analyzed by regression technique and a predication model was obtained after three trends of testing (linear, Exponential and polynomial). The exponential trend was the best $\left(\mathrm{R}^{2}=0.9368\right)$. The prediction model was validated by comparing predicted and measured data and good fit of data were obtained. Therefore, the use of Bentonite to remove chromium is considered as a very successful method, and it can be a solution to the problem of industrial waste resulting from the tanning industry.
\end{abstract}

Keywords: Wastewater, Tannery, Bentonite, Heavy Metals, Sudan

\section{Introduction}

Wastewater is the liquid waste resulting from private, public or commercial areas, or from industrial processes in addition to infiltration into sewers. Industry waste are commonly classified into three categories: liquid waste, solid wastes, and gaseous wastes ${ }^{[1]}$. Industrial wastewater are usually more polluted than the other sources of wastewater ${ }^{[2]}$. According to type and size of industry the wastewater characteristics vary in both flow and pollutional strength ${ }^{[1]}$.

In tanneries based on chemical processes animal hides and skin transforms to useful materials which are used in manufacturing leather products $[3,4,5]$. The effluents of tanning industry comprises of organic and inorganic pollutants which is classified as the highest pollutants compared with the other industrial wastes ${ }^{[6,7]}$.

The modern sector of tanning industry in Sudan dated back to 1945 . In 1965 the development in tanning industry with establishment of Khartoum tannery ${ }^{[8]}$. Numbers of techniques have been proposed to remove heavy metals from tanning effluent such as chemical precipitation, ion exchange, and reverse osmosis. These methods are either needs high cost or the performance are low ${ }^{[9]}$.

Bentonite is defined as clay rocks which is formed by the weathering of volcanic ash and have a wide range of applications in industry ${ }^{[10,11]}$.

Khartoum North is the major and biggest industrial area in Sudan, causing industrial hazards for human and environment. There are many factories such as: chemical, plastic, paints, oil mills and soap manufacturing plant, food processing, steel plating and pharmaceutical labs.Africa tannery is located in Khartoum North -NO: 26 -Block: 2 Area: $400 \mathrm{~m}^{2}$. Africa tannery was established at 2005 with production capacity about 300 leathers/day for leather Export and internal production. Africa tannery waste treatment by using on-site disposal (sedimentation tank $6 * 4 * 3 \mathrm{~m}$ ). Amount of water consumption in industry about $300-400 \mathrm{~m}^{3} /$ day.

Tannery effluent containing chromium is one of the most 
obvious problems in leather industry. Africa tannery wastewater is discharged directly to the public sewer which may cause difficulties in the sewer system and to the wastewater treatment plants if not pretreated. The main objective of this study is to assess the effect of adding a cheap material such as Bentonite to remove chromium from Africa tannery wastewater.

\section{Materials and Methods}

The samples were collected in glass bottle ( 8 liters) and were corked immediately. All the samples were brought to the laboratory and stored at $4^{\circ} \mathrm{C}$ temperatures in refrigerator till the analyses were completed. All chemical analysis were done in evening or the following days. This sample was used for the tests given below. The sampling procedure according to "Standard Methods for Examination of Water and Wastewater" [12].

\subsection{Samples Preparation}

Sample collected from study area was divided into five groups in beakers with total capacity of 1 liter. Different doses of bentonite were added into each beaker (e.g. 5, 10, 15, and 20 gram.). The retention time of samples 6 hours after addition of doses before the applications. Table 1 lists the compositions of the samples.

Table 1. Samples compositions.

\begin{tabular}{ll}
\hline Sample Group & Bentonite (gram) \\
\hline A & - \\
B & 5 \\
C & 10 \\
D & 15 \\
E & 20 \\
\hline
\end{tabular}

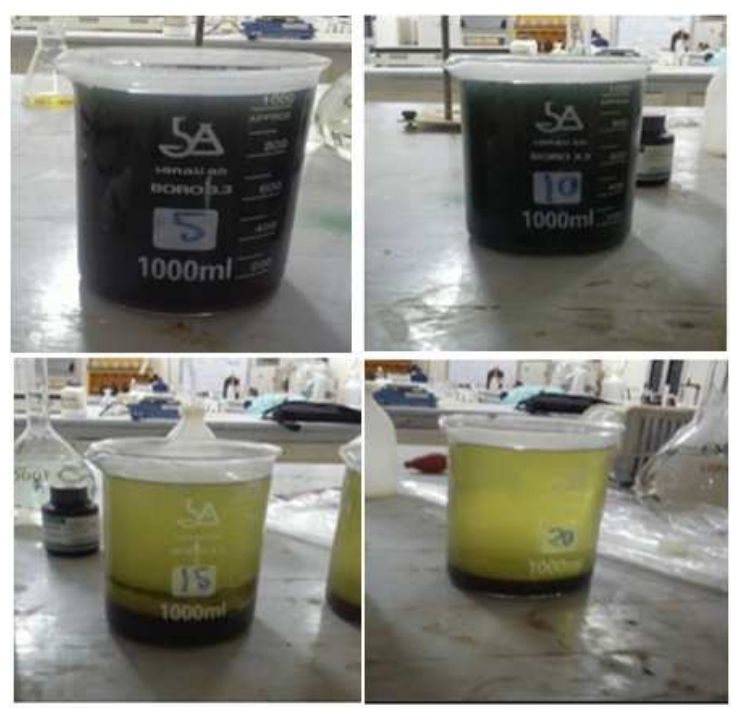

Figure (1). Samples Prepreation.

\subsection{Bentonite Properties}

The chemical composition of Bentonite used in this study was investigated using ICP test.

\section{Results and Discussions}

Table (2) shows the chemical composition of bentonite used as heavy metal removal.

The addition of bentonite to the Africa tannery wastewater causes a huge reduction in chrome as shown in figure 2 . At a concentration of 20 gram this reduction reaches $0.198 \mathrm{mg} / \mathrm{L}$ which is a high percentage of removal.

Also, Figures 3 and 4 shows that the increase in bentonite concentration decreases the values of $\mathrm{BOD}_{5}$ and $\mathrm{COD}$ until reach concentration 15 gram of bentonite and then the values of BOD5 and COD increases at 20 gram bentonite.

As far as the effect on choloride, O\&G, T.SS are concerned, figures 5 to 7 show that the increasing of bentonite concentration decreases the chloride, O\&G, T.SS in difference degree of removal efficiency.

As shown in figure 8 increasing of bentonite concentration decreases the $\mathrm{pH}$ values till the concentration of bentonite 15 gram, after this point any addition of bentonite increase the $\mathrm{pH}$ values.

Table 3 shows the removal percentage of different types of tests carried out.

Table 2. Chemical Composition and Loss on Ignition of Bentonite.

\begin{tabular}{lll}
\hline Elements & Unit & Result \\
\hline $\mathrm{Al}_{2} \mathrm{O}_{3}$ & & 10.04 \\
$\mathrm{CaO}$ & $\mathrm{Wt} \%$ & 1.207 \\
$\mathrm{Fe}_{2} \mathrm{O}_{3}$ & & 18.30 \\
$\mathrm{~K}_{2} \mathrm{O}$ & & 0.0111 \\
$\mathrm{MgO}$ & & 0.8620 \\
$\mathrm{MnO}$ & $\mathrm{ppm}$ & 2617 \\
$\mathrm{Na}_{2} \mathrm{O}$ & & 2.866 \\
$\mathrm{P}_{2} \mathrm{O}_{5}$ & $\mathrm{Wt} \%$ & 2.125 \\
$\mathrm{LiO}_{2}$ & & 33.89 \\
$\mathrm{TiO}_{2}$ & $\mathrm{ppm}$ & 1.469 \\
$\mathrm{SiO}_{2}$ & & 48.94 \\
$\mathrm{L.O} \mathrm{O}$ & $\mathrm{Wt} \%$ & 14.38 \\
\hline
\end{tabular}

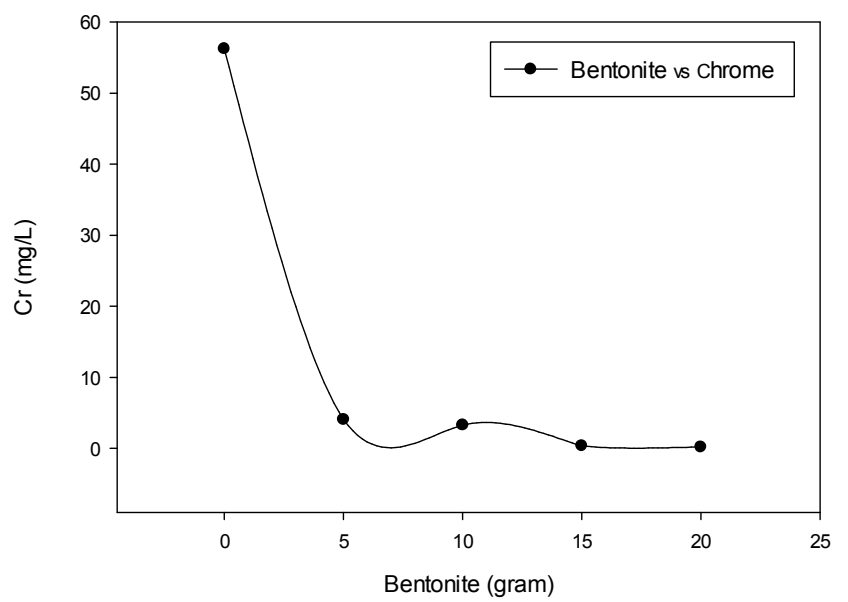

Figure (2). Bentonite additive vs. chrome. 


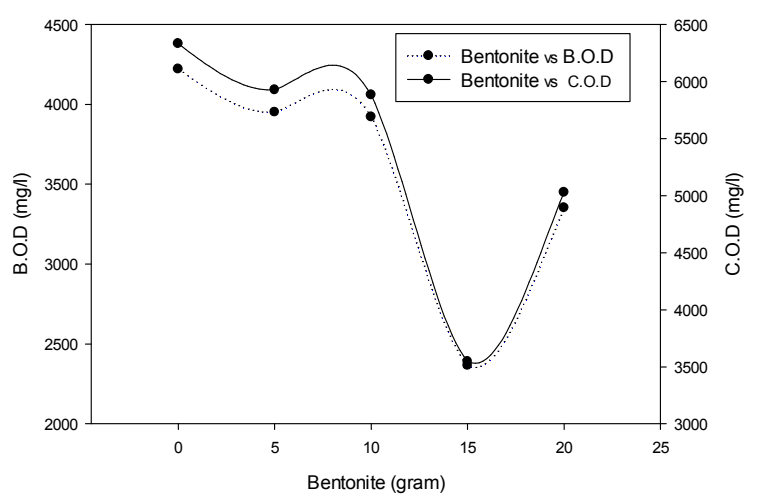

Figure (3). Bentonite additive vs. B.O.D. and C.O.D.

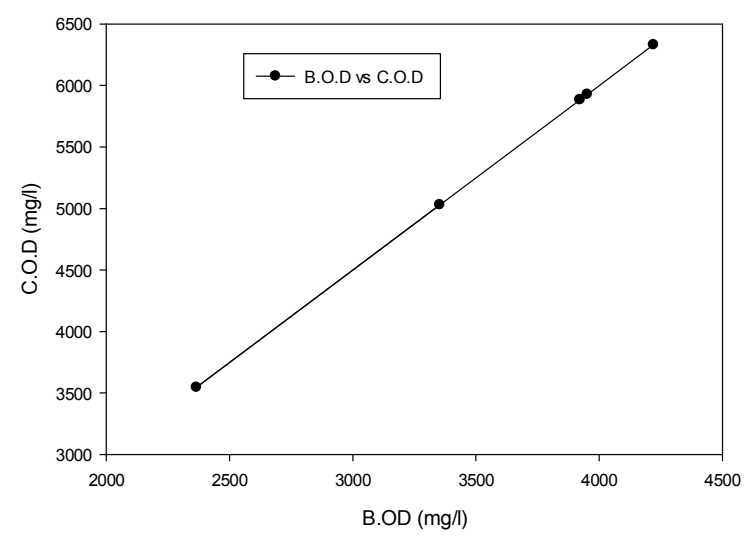

Figure (4). B.O.D. and C.O.D. Relationship

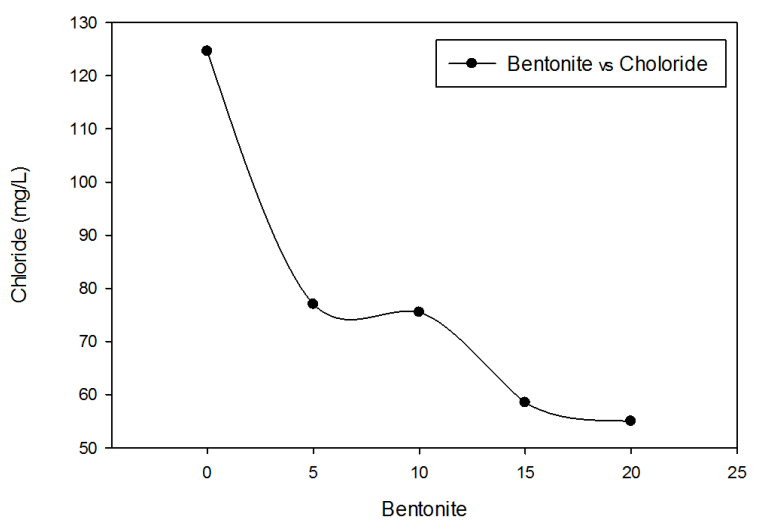

Figure (5). Bentonite additive vs. Chloride.

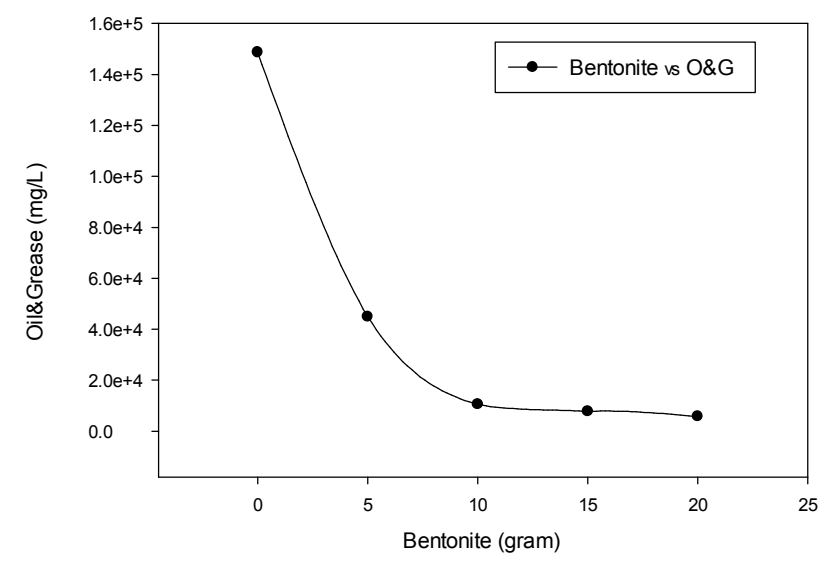

Figure (6). Bentonite additive vs. $O \& G$.

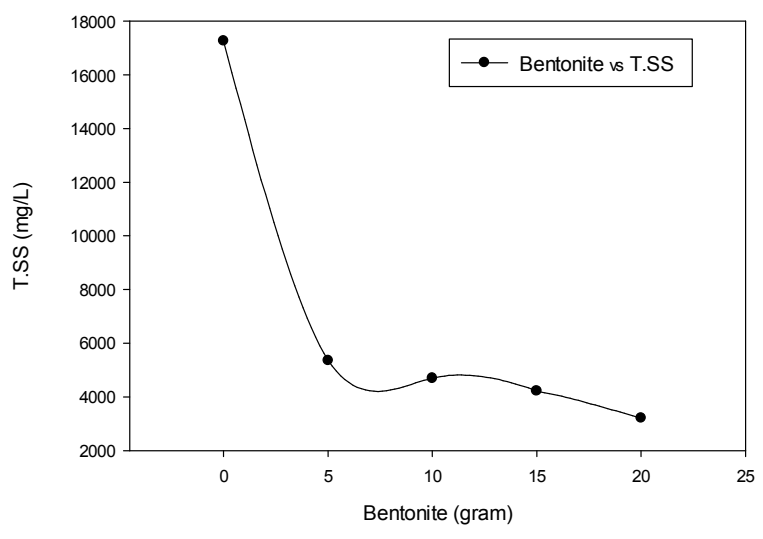

Figure (7). Bentonite additive vs. TSS.

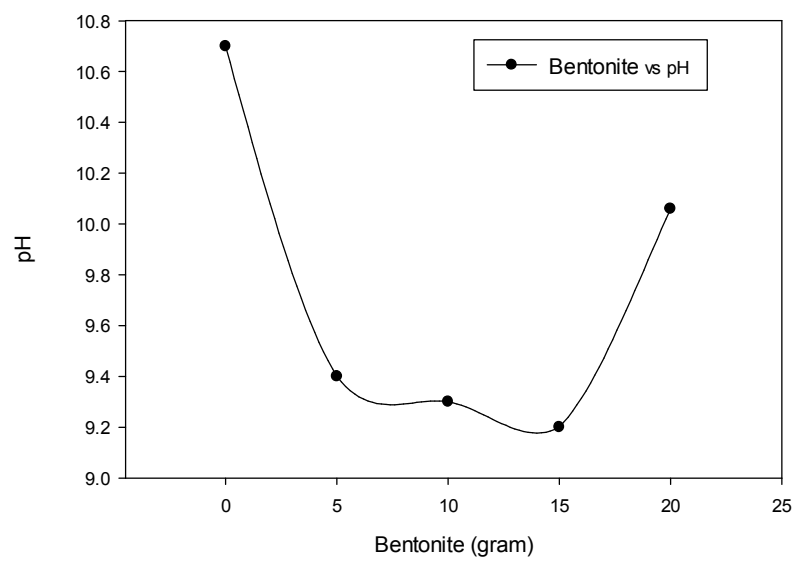

Figure (8). Bentonite additive vs. $p H$.

Table 3. Removal Percentage includes total $\mathrm{Cr}$.

\begin{tabular}{llllll}
\hline \multirow{2}{*}{$\begin{array}{l}\text { Bentonite } \\
\text { Concentration }\end{array}$} & \multicolumn{6}{l}{ Removal \% } \\
\cline { 2 - 6 } Cr & C.O.D & O\&G & T.SS & cl $^{-1}$ \\
\hline gram & 92 & 37 & 69 & 68 & 38 \\
15 gram & 94 & 39 & 92 & 72 & 39 \\
20 gram & 99 & 44 & 94 & 75 & 53 \\
\hline
\end{tabular}

\section{Empirical Model}

The Empirical Model was developed using Regression Analysis Techniques. Regression analysis is a statistical tool for the investigation of relationships between variables. The chrome Concentration (C) related to the amount of the bentonite (B). Figures 9 and 10 show the trend lines which represent the above relationship. The measured data was used to develop the empirical model to predict the effect of increasing bentonite amount on chrome removal. The Exponential trend line was the best Empirical model to predict the chrome as function of bentonite amount.

Fig 10 shows the relation between measured and predicted values of chrome. The empirical Equation 1 was found to predict satisfactorily the chrome with

$$
\begin{array}{r}
R^{2}=0.9368 \\
\mathrm{C}=34.574 \mathrm{e}^{-0.274 \mathrm{~B}}
\end{array}
$$

Table 4 shows the constants for various trend lines for the relationships between chrome and bentonite amount. Fig 11 
shows the measured and predicted data.

Table 4. The empirical model constant to compute chrome.

\begin{tabular}{llllll}
\hline Trend lines & a & b & c & d & $\mathbf{R}^{2}$ \\
\hline Exponential & 34.574 & -0.274 & - & - & 0.9368 \\
Polynomial Order 2 & 0.2926 & -8.1776 & 50.772 & - & 0.8794 \\
Linear & -2.326 & 36.143 & - & - & 0.566 \\
\hline
\end{tabular}

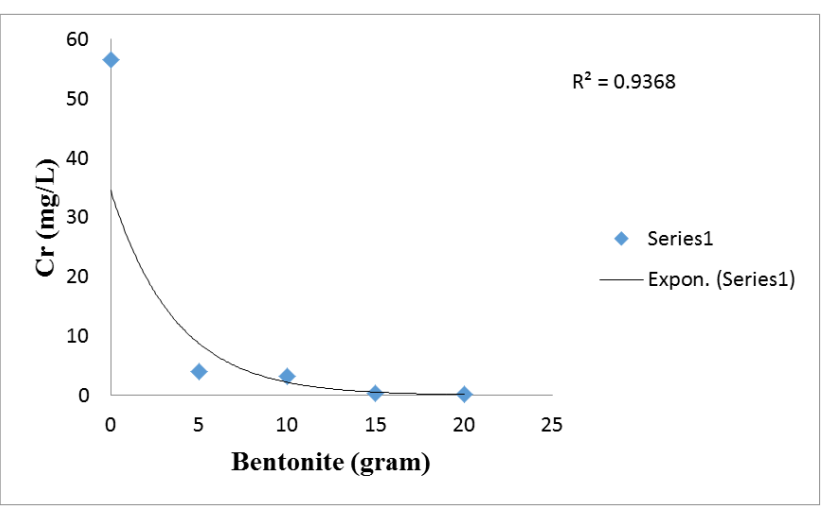

Figure (9). The change in chrome as a function of bentonite amount Expon trend line.

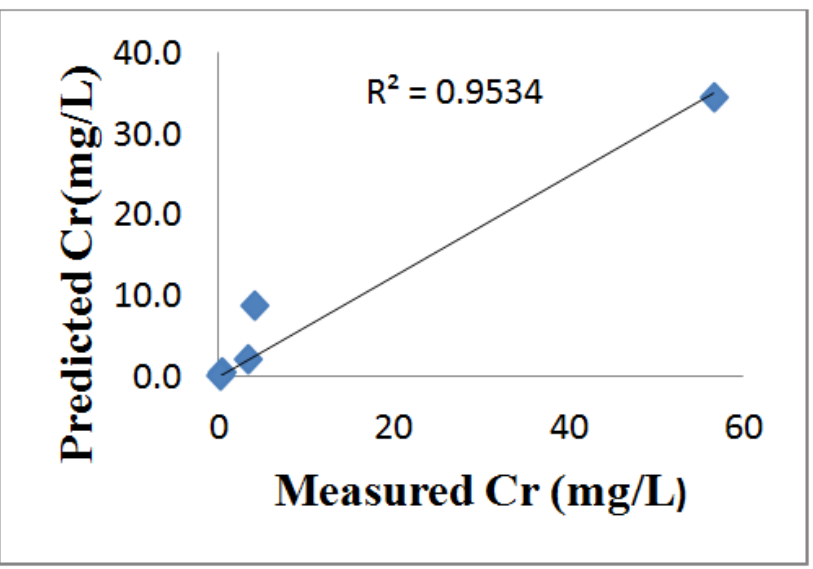

Figure (10). Predicted and measured values of chrome.

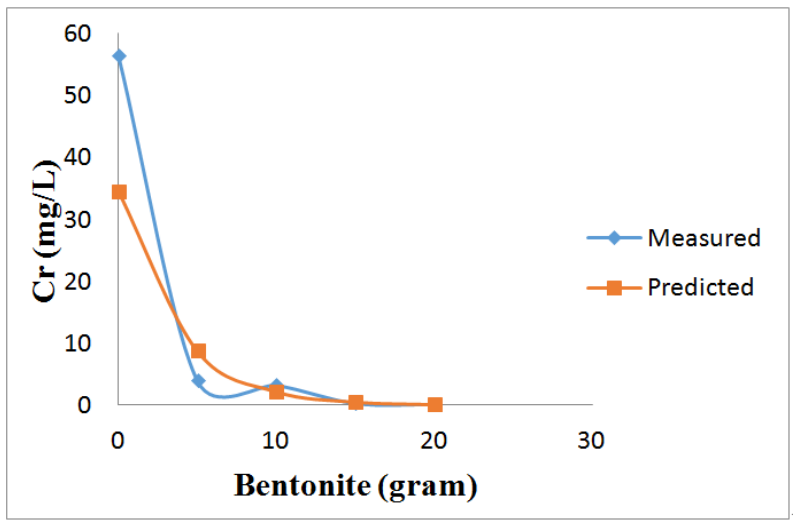

Figure (11). Measured and predicted data.

\section{Conclusions and Recommendations}

Based on the results of the tests performed, the following conclusions were drawn:
- The tannery effluent analyzed was found to contain excessively high amount of $\mathrm{Cr}$ hazardous if returned back to the environment untreated

- Adding Bentonite to Africa tannery wastewater remove chrome in different degrees of efficiency.

- Chloride, O\&G and T.SS for wastewater collected from Africa tannery decreases with increase in Bentonite concentration.

- Addition of $15 \mathrm{gram}$ of Bentonite concentration for the selected samples gives the lowest values of BOD of $2365 \mathrm{mg} / \mathrm{l}$ and COD of $3547 \mathrm{mg} / \mathrm{l}$.

- Based on the above result of this study 15 gram of Bentonite concentration is recommended as an optimum dose.

- The study recommends the use Bentonite in the field of tannery wastewater treatment.

- Developed models can be used to predict chrome values with different Bentonite concentration.

\section{References}

[1] Schroder.J.H. (1982) .Aspect of the coastal zone management of Sudanese Red sea: characteristic and Resources, pollution, conservation research, - Inst. Environmental studies, University of Khartoum, Environmental Research Reports, Nr.3, 53S.

[2] S.k.Garg, (2010), Sewage disposal and air pollution engineering PB, Khanna Publishers.

[3] Kuppusamy Ranganathan, Shreedevi D. Kabadgi (2011), Studies on Feasibility of Reverse Osmosis (Membrane) Technology for Treatment of Tannery Wastewater, Journal of Environmental Protection, 2, 37-46.

[4] VARSHA MIDHA and APURBA DEY (2008), BIOLOGICAL TREATMENT OF TANNERY WASTEWATER FOR SULFIDE REMOVAL, Int. J. Chem. Sci.: 6(2), 2008, 472-486.

[5] S. Hammami, A. Ouejhani, N. Bellakhal, M. Dachraoui, Application of Doehlert matrix to determine the optimal conditions of electrochemical treatment of tannery effluents J. Hazard. Mater. 163 (2009) 251-258.

[6] Alebel Abebe Belay (2010), Impacts of Chromium from Tannery Effluent and Evaluation of Alternative Treatment Options, Journal of Environmental Protection, 1, 53-58.

[7] X. Josephine Jenitta, V. Daphne Vivienne Gnanasalomi, J. Joel Gnanadoss, (2013), TREATMENT OF LEATHER EFFLUENTS AND WASTE USING FUNGI, International Journal of Computing Algorithm Volume: 02, October 2013, Pages: 294-298.

[8] Elbeely, K., Hassan (2011), Does privatization work? The story of Sudan's White Nile tannery, Jou of US.China public administration, volume 8 No. 4 .

[9] Barkat, M., Chegrouche, S., Mellah, A., Bensmain, B., Nibou, D. and Boufatit, M. (2014) Application of Algerian Bentonite in the Removal of Cadmium (II) and Chromium (VI) from Aqueous Solutions. Journal of Surface Engineered Materials and Advanced Technology, 4, 210-226. 
[10] M.I. Abdou, A.M. Al-sabagh, M.M. Dardir (2013), Evaluation of Egyptian bentonite and nano-bentonite as drilling mud, Egyptian Journal of Petroleum Volume 22, PP. 53-59.

[11] M.Onal (2006), Phyisco-chemical properties of Bentonite: An Overview, commun. fac. sci. Univ. Ank. series B Volume52(2). PP. 7-21.
[12] American Public Health Organization (1992), Standard Methods for the Examination of water and wastewater, 18th edition. 